\title{
Irrigation Versus Suction Alone During Laparoscopic Appendectomy for Uncomplicated Acute Appendicitis
}

\author{
Tae Gyeong Lee ${ }^{1,2}$, Soomin Nam${ }^{1}$, Hyung Soon Lee ${ }^{1}$, Jin Ho Lee ${ }^{1}$, Young Ki Hong ${ }^{1}$, Jung Gu Kang ${ }^{1}$ \\ ${ }^{1}$ Department of Surgery, National Health Insurance Service Ilsan Hospital, Goyang; ${ }^{2}$ Department of Surgery, Yonsei University College of \\ Medicine, Seoul, Korea
}

Purpose: To compare the surgical outcomes of peritoneal irrigation versus suction alone during laparoscopic appendectomy and to identify the risk factors of surgical site infection in patients with uncomplicated acute appendicitis.

Methods: Data from patients with uncomplicated acute appendicitis between January 2014 and March 2016 were reviewed. We compared the irrigation and suction alone groups with regard to the following parameters: postoperative complication incidence rate, length of hospital stay, operation time, time to flatus, time to diet commencement, and duration of postoperative antibiotic.

Results: A total of 578 patients underwent laparoscopic appendectomy for uncomplicated acute appendicitis. Twenty-five patients were excluded from the analysis because of need for drain insertion, loss to follow-up, simultaneous surgery for another indication, presence of an appendix tumor, or pregnancy. A total of 207 patients (37.4\%) had undergone irrigation, and 346 patients (62.6\%) received suction alone during laparoscopic appendectomy. The preoperative fever rate was significantly higher in the irrigation group than in the suction alone group. Operative time was also significantly longer in the irrigation group than in the suction alone group ( $53.8 \pm 18.5$ minutes vs. $57.8 \pm 21.4$ minutes, $\mathrm{P}=0.027)$. The postoperative complication rate was higher in the irrigation group than in the suction alone group $(4.5 \%$ vs. $12.6 \%, \mathrm{P}=0.001)$. Multiple logistic regression analysis showed that irrigation and preoperative fever were risk factors for surgical site infection after laparoscopic appendectomy for uncomplicated acute appendicitis.

Conclusion: There is no advantage to irrigating the peritoneal cavity over suction alone during laparoscopic appendectomy for uncomplicated acute appendicitis. Irrigation may actually prolong the operative time and therefore be detrimental.

Keywords: Appendicitis; Appendectomy; Laparoscopy; Therapeutic irrigation

\section{INTRODUCTION}

Laparoscopic appendectomy (LA) has been widely accepted over the last two decades as the standard surgical treatment for appendicitis [1]. Previous studies have shown that LA offers several advantages over open appendectomy, including decreased recovery time,

Received: April 17, 2019 • Accepted: June 25, 2019

Correspondence to: Hyung Soon Lee, M.D.

Department of Surgery, National Health Insurance Service Ilsan Hospital, 100 Ilsan-ro, Ilsandong-gu, Goyang 10444, Korea

Tel: +82-31-900-0975, Fax: +82-31-900-0138

E-mail: soon0925@nhimc.or.kr

ORCID: https://orcid.org/0000-0001-9825-8648

(C) 2020 The Korean Society of Coloproctology

This is an open-access article distributed under the terms of the Creative Commons Attribution NonCommercial License (https://creativecommons.org/licenses/by-nc/4.0) which permits unrestricted noncommercial use, distribution, and reproduction in any medium, provided the original work is properly cited. a shorter hospital stay, and a lower rate of wound infection $[2,3]$.

Complicated appendicitis is defined as acute appendicitis with associated peritonitis, rupture, gangrene, or intra-abdominal abscess (IAA) and accounts for $14 \%-55 \%$ of all cases of appendicitis [4]. Complicated appendicitis is associated with a higher incidence of major complications after appendectomy $[5,6]$. Major postoperative complications after appendectomy include wound infection and IAA, which are common causes of prolonged hospital stay, greater cost, and lower quality of life [7]. Previous studies have addressed several factors that contribute to IAA formation after LA, such as obesity, appendicular inflammation status, preoperative leukocytosis, and long operative time [8]. However, there is limited information regarding the IAA risk factors. The association between risk factors and IAA remains controversial.

Previous studies have suggested that peritoneal irrigation during LA for complicated appendicitis could reduce the incidence of 
IAA $[9,10]$. This idea came from the phrase "dilution is the solution to pollution." Many surgical centers perform irrigation during LA despite the absence of guidelines to recommend this practice $[5,11]$. The efficacy of irrigation during LA to reduce the risk of IAA remains debatable. A few studies have evaluated the effectiveness of irrigation during LA; however, most focused on complicated appendicitis $[9,12]$. In addition, there is no evidence for irrigation during LA in uncomplicated appendicitis cases.

The purpose of this study was to compare surgical outcomes of peritoneal irrigation versus suction alone during LA. We also sought to identify risk factors of surgical site infection (SSI) after LA in uncomplicated acute appendicitis.

\section{METHODS}

Medical records were retrospectively reviewed to identify patients who underwent LA for uncomplicated appendicitis at National Health Insurance Service Ilsan Hospital between January 2014 and December 2016. The study was approved by the Institutional Review Board of National Health Insurance Service Ilsan Hospital and informed consent was waived. (NHIMC 2017-07-018). Patients aged $18-80$ years were considered for inclusion. A diagnosis of acute appendicitis was suspected when a patient presented with a history of right lower quadrant abdominal pain or periumbilical pain (that migrated to the right lower quadrant) with nausea and/ or vomiting, and right lower quadrant abdominal tenderness on physical examination. Uncomplicated appendicitis was defined as an inflamed but grossly intact, nongangrenous, nonsuppurative appendix with no associated abscess or peritonitis. Diagnosis of uncomplicated appendicitis was confirmed using contrast-enhanced abdomino-pelvic computed tomography. A general surgeon performed LA in this study.

\section{LA surgical procedure}

After pneumoperitoneum was achieved, a $30^{\circ} 10-\mathrm{mm}$ rigid scope was placed into the peritoneal cavity through a $1.5-\mathrm{cm}$ infraumbilical incision. Two additional 5-mm incisions were made in the suprapubic area and the left lower quadrant for working port insertion. The mesoappendix was divided using electrocauterization, and appendiceal vessels were ligated with endoscopic metal clips. The appendiceal base was ligated and transected using Endoloops (Ethicon, Cincinnati, OH, USA). Peritoneal irrigation was performed at the surgeon's discretion based on operative findings and preference. If irrigation was performed, a 1-L bag of sterile normal saline was attached to the irrigation device for this purpose. The appendix specimens were retracted using a specimen retrieval bag and removed through the infraumbilical incision. The infraumbilical fascia was closed with running 2-0 absorbable sutures. The skin incisions were closed using a stapler device.

\section{Postoperative management}

Postoperatively, all of the patients were treated with an intrave- nous second-generation cephalosporin. The type and length of antibiotic course were chosen based on operative findings and the patient's clinical condition. Patients were allowed to have sips of water on the day of the first flatus. They were then advanced to a regular diet dependent on individual condition. Patients were discharged when they could tolerate a regular diet and had no other specific symptoms.

\section{Patient characteristics and surgical outcomes}

The clinical characteristics included in the analysis were age, sex, body mass index (BMI), American Society of Anesthesiologists (ASA) physical status classification, abdominal pain duration, preoperative fever, appendix position, and laboratory data (white blood cell [WBC] count, neutrophil percentage, hemoglobin, Creactive protein, total bilirubin, and albumin). Surgical outcomes were operative time, time to the first flatus, time to regular diet, length of hospital stay, postoperative fever, intravenous antibiotics duration, and postoperative complications.

Pre- and postoperative fever were defined as body temperature $>37.8^{\circ} \mathrm{C}$ during the pre- and postoperative period, respectively. The operative time was defined as the time from skin incision to application of final wound dressing. Time to the first flatus was defined based on patient notification of the first gas passage after surgery. Time to a regular diet was defined as the time from end of surgery until a soft diet was started. Hospital length of stay was the number of days from the day of surgery (day 0 ) to discharge. Postoperative complications were assessed using the ClavienDindo classification [13]. An SSI was defined as an infection occurring within 30 days after surgery that either affected the incision or deep tissue at the operative site [14]. Patients with SSI had at least one of the following signs or symptoms: fever $\left(>37.8^{\circ} \mathrm{C}\right)$, localized pain or tenderness, localized swelling, or redness. Wound infection was defined as the presence of the following within 30 days of surgery: purulent discharge, culture-positive wound discharge, pain/tenderness, localized swelling, erythema, or cellulitis [15]. Urinary retention was defined as inability to voluntarily urinate despite the presence of a distended bladder on physical examination [16]. IAA and incomplete appendectomy were diagnosed using abdomino-pelvic computed tomography.

\section{Statistical analysis}

Data are presented as number of patients (\%) or mean \pm standard deviation. Categorical variables were compared using the chisquare or Fisher exact test. Continuous variables were compared using Student t-test. Categorical variables were analyzed using chi-square tests. Factors with P-value $<0.05$ on univariate analysis were included in the multivariate logistic regression analysis to identify the risk factors. Statistical analyses were performed using IBM SPSS ver. 18.0 (IBM Co., Armonk, NY, USA). P-values $<0.05$ were considered statistically significant. 


\section{RESULTS}

\section{Patient characteristics}

A total of 578 patients underwent LA for uncomplicated appendicitis. Twenty-five patients were excluded from the analysis for the following reasons: drain insertion required during surgery $(\mathrm{n}=$ 18), loss to follow-up $(n=1)$, simultaneous surgery for another indication $(\mathrm{n}=3)$, diagnosed with an appendix tumor after surgery $(n=2)$, and pregnancy $(n=1)$. Among the remaining 553 patients, suction alone was used during LA in 346 (62.6\%), while irrigation was performed in 207 (37.4\%). The patient characteristics at the time of diagnosis of acute appendicitis are listed in Table 1. There was a significant difference in preoperative fever rate between the suction only and irrigation groups. However, there were no significant differences between the groups with regard to age, sex, BMI, ASA physical status classification, duration of abdominal pain, type of appendix, WBC count, neutrophil percentage, hemoglobin, C-reactive protein, total bilirubin, or albumin.

\section{Surgical outcomes}

Mean operative time was significantly longer in the irrigation group than in the suction only group (Table 2). The incidence of postoperative fever was also significantly higher in the irrigation group than in the suction only group. However, there were no significant differences between the groups with regard to time to first flatus, time to regular diet, length of hospital stay, or duration of intravenous antibiotics. The overall postoperative complication rate was significantly higher in the irrigation group than in the suction only group (Table 3 ). The SSI rate was also significantly higher in the irrigation group.

Table 1. Patient characteristics at diagnosis of acute appendicitis

\begin{tabular}{lccc}
\hline Characteristic & $\begin{array}{c}\text { Suction only } \\
(\mathrm{n}=346)\end{array}$ & $\begin{array}{c}\text { Irrigation } \\
(\mathrm{n}=207)\end{array}$ & P-value \\
\hline Age $(\mathrm{yr})$ & $39.8 \pm 15.5$ & $40.6 \pm 15.6$ & 0.581 \\
Male sex & $160(46.2)$ & $111(53.6)$ & 0.093 \\
\hline Body mass index $\left(\mathrm{kg} / \mathrm{m}^{2}\right)$ & $23.1 \pm 3.2$ & $23.5 \pm 3.4$ & 0.219 \\
ASA PS classification $\geq \mathrm{III}$ & $12(3.5)$ & $6(2.9)$ & 0.715 \\
Duration of abdominal pain & $1.6 \pm 1.1$ & $1.5 \pm 0.8$ & 0.263 \\
Preoperative fever & $20(5.8)$ & $28(13.5)$ & 0.002 \\
Retrocecal type appendix & $71(20.5)$ & $56(27.1)$ & 0.077 \\
White blood cell $\left(\times 10^{3} \mathrm{cell} / \mathrm{sL}\right)$ & $12.4 \pm 3.9$ & $12.8 \pm 4.3$ & 0.276 \\
Neutrophil percentage $(\%)$ & $76.0 \pm 10.8$ & $75.6 \pm 10.8$ & 0.701 \\
Hemoglobin $(\mathrm{g} / \mathrm{dL})$ & $14.1 \pm 1.5$ & $14.5 \pm 3.6$ & 0.115 \\
C-reactive protein $(\mathrm{mg} / \mathrm{dL})$ & $2.4 \pm 3.4$ & $2.3 \pm 3.2$ & 0.822 \\
Total bilirubin $(\mathrm{mg} / \mathrm{dL})$ & $1.2 \pm 0.5$ & $1.2 \pm 0.5$ & 0.837 \\
Albumin $(\mathrm{g} / \mathrm{dL})$ & $4.2 \pm 0.3$ & $4.1 \pm 0.3$ & 0.273 \\
\hline
\end{tabular}

Values are presented as mean \pm standard deviation or number (\%). ASA PS, American Society of Anesthesiologists physical status.
Risk factors of SSI after LA for uncomplicated appendicitis Univariate analysis identified preoperative fever and irrigation as risk factors of SSI after LA for uncomplicated appendicitis. These findings were confirmed in the multiple logistic regression analysis (Table 4).

\section{DISCUSSION}

There was significantly longer operative time and a higher postoperative complication rate in the irrigation group than in the suction only group. Peritoneal irrigation was also identified as a risk factor of SSI after LA for uncomplicated appendicitis. These results suggest that peritoneal cavity irrigation offers no advantage over suction performed during LA for uncomplicated acute appendicitis.

For many years, there was a vague hypothesis that peritoneal ir-

Table 2. Surgical outcomes by group

\begin{tabular}{lccc}
\hline Variable & $\begin{array}{c}\text { Suction only } \\
(\mathrm{n}=346)\end{array}$ & $\begin{array}{c}\text { Irrigation } \\
(\mathrm{n}=207)\end{array}$ & P-value \\
\hline Operative time (min) & $53.8 \pm 18.5$ & $57.9 \pm 21.4$ & 0.027 \\
Operative time over 90 min & $15(4.3)$ & $13(6.3)$ & 0.313 \\
Time to the first flatus (day) & $1.2 \pm 0.7$ & $1.2 \pm 0.7$ & 0.979 \\
Time to regular diet (day) & $2.1 \pm 0.7$ & $2.0 \pm 0.8$ & 0.073 \\
Length of hospital stay (day) & $2.8 \pm 0.8$ & $2.9 \pm 1.2$ & 0.266 \\
Postoperative fever & $40(11.6)$ & $38(18.4)$ & 0.026 \\
Intravenous antibiotics (day) & $1.3 \pm 1.0$ & $1.5 \pm 1.2$ & 0.111 \\
\hline
\end{tabular}

Values are presented as mean \pm standard deviation or number (\%).

Table 3. Postoperative complications by group

\begin{tabular}{|c|c|c|c|}
\hline Variable & $\begin{array}{l}\text { Suction only } \\
(\mathrm{n}=346)\end{array}$ & $\begin{array}{l}\text { Irrigation } \\
(n=207)\end{array}$ & P-value \\
\hline Overall complications & $16(4.6)$ & $26(12.6)$ & 0.001 \\
\hline Surgical site infections & $15(4.3)$ & $25(12.1)$ & 0.001 \\
\hline \multicolumn{4}{|l|}{ Grade I } \\
\hline Wound infection ${ }^{\mathrm{a}}$ & $9(2.6)$ & $14(6.8)$ & \\
\hline Urinary retention & $1(0.3)$ & $1(0.5)$ & \\
\hline \multicolumn{4}{|l|}{ Grade ॥ } \\
\hline Postoperative fever ${ }^{\mathrm{b}}$ & $1(0.3)$ & $3(1.4)$ & \\
\hline Intra-abdominal abscess & $2(0.6)$ & $5(2.4)$ & \\
\hline \multicolumn{4}{|l|}{ Grade IIla } \\
\hline Wound infection & $2(0.6)$ & $3(1.4)$ & \\
\hline \multicolumn{4}{|l|}{ Grade IIIb } \\
\hline Intra-abdominal abscess & $1(0.3)$ & $0(0.0)$ & \\
\hline
\end{tabular}

Values are presented as number (\%).

Complication analysis employed the Clavien-Dindo classification.

${ }^{a}$ Wound treated at bedside. ${ }^{\mathrm{b}}$ The patients who required antibiotic escalation due to fever. 
Table 4. Univariate and multivariate logistic regression analyses of risk factors for surgical site infection after laparoscopic appendectomy

\begin{tabular}{|c|c|c|c|}
\hline Variable & Hazard ratio & $95 \% \mathrm{Cl}$ & P-value \\
\hline \multicolumn{4}{|l|}{ Univariate analyses } \\
\hline \multicolumn{4}{|l|}{ Age (yr) } \\
\hline$<65$ vs. $\geq 65$ & 1.504 & $0.388-5.835$ & 0.555 \\
\hline \multicolumn{4}{|l|}{ Sex } \\
\hline Male vs. female & 1.371 & $0.676-2.779$ & 0.381 \\
\hline \multicolumn{4}{|l|}{ ASA PS classification } \\
\hline$<|| \mid$ vs. $\geq|| \mid$ & 0.831 & $0.094-7.308$ & 0.867 \\
\hline \multicolumn{4}{|l|}{ Body mass index $\left(\mathrm{kg} / \mathrm{m}^{2}\right)$} \\
\hline$<30$ vs. $\geq 30$ & 2.534 & 0.595-10.794 & 0.209 \\
\hline \multicolumn{4}{|l|}{ WBC count (cells/ $\mu \mathrm{L})$} \\
\hline$<20,000$ vs. $\geq 20,000$ & 2.119 & $0.592-7.587$ & 0.248 \\
\hline \multicolumn{4}{|l|}{ C-reactive protein (mg/dL) } \\
\hline$<5$ vs. $\geq 5$ & 0.611 & $0.213-2.047$ & 0.473 \\
\hline \multicolumn{4}{|l|}{ Operative time (min) } \\
\hline$<90$ vs. $\geq 90$ & 1.764 & $0.474-6.572$ & 0.398 \\
\hline \multicolumn{4}{|l|}{ Reactive fluid } \\
\hline No vs. yes & 1.525 & $0.745-3.123$ & 0.248 \\
\hline \multicolumn{4}{|l|}{ Preoperative fever } \\
\hline No vs. yes & 3.932 & $1.684-9.181$ & 0.002 \\
\hline \multicolumn{4}{|l|}{ Irrigation } \\
\hline No vs. yes & 2.082 & $1.014-4.274$ & 0.046 \\
\hline \multicolumn{4}{|l|}{ Multivariate analyses } \\
\hline \multicolumn{4}{|l|}{ Preoperative fever } \\
\hline No vs. yes & 4.058 & $1.844-8.929$ & $<0.001$ \\
\hline \multicolumn{4}{|l|}{ Irrigation } \\
\hline No vs. yes & 2.639 & $1.338-5.207$ & 0.005 \\
\hline
\end{tabular}

$\mathrm{Cl}$, confidence interval; ASA PS, American Society of Anesthesiologists physical status; WBC, white blood cell.

rigation would reduce the incidence of IAA in this setting [12]. However, peritoneal contamination is not a simple problem that is eliminated by irrigation. As our data suggest, peritoneal irrigation may even be harmful. St Peter et al. [17] suggested that bacteria adhered to peritoneal mesothelial cells; unfortunately, irrigation did not decrease the microorganism load of the peritoneum. Instead, irrigation may spread this contamination and dilute phagocytosis mediators such as opsonic proteins and immunoglobulins $[18,19]$. In accordance with previous studies, we found a significantly higher SSI rate in the irrigation group than in the suction only group. Multiple logistic regression analysis confirmed that irrigation was a risk factor of SSI after LA for uncomplicated appendicitis. Therefore, one must carefully consider whether peritoneal irrigation is indicated during LA for uncomplicated appendicitis.
The current investigation offers new information with regard to the efficacy of irrigation during LA. We only included patients with uncomplicated appendicitis. Most previous studies assessed patients with complicated appendicitis or analyzed a heterogeneous group of uncomplicated and complicated appendicitis cases. Cho et al. [5] reported that, when the decision to perform peritoneal irrigation was at the surgeon's discretion, it was performed in $20.4 \%$ of patients with suppurative appendicitis. Snow et al. [20] performed a randomized controlled trial to compare outcomes following peritoneal irrigation or suction alone during LA. However, their study population was a heterogeneous mix of uncomplicated and complicated appendicitis. These findings suggest that irrigation may be routinely performed in LA at the surgeon's discretion regardless of the status of peritoneal inflammation. However, these practices were not evidence based. The status of abdominal inflammation may be affected by peritoneal irrigation during LA and by postoperative outcome. Therefore, the patients must be studied separately according to uncomplicated or complicated appendicitis. It is also important to assess outcomes in patients with uncomplicated appendicitis.

The impact of operative time on SSI remains debatable. Fraser et al. [21] evaluated the predictors of postoperative IAA in patients with perforated appendicitis and found no correlation between operative time and IAA. However, one may assume that more time-consuming cases are more complex and therefore have a higher rate of intra-abdominal complications. Schlottmann et al. [8] demonstrated that surgical time $>90$ minutes increased the risk of IAA after LA. Extended pneumoperitoneum, irrigation, or other surgical maneuvers may also increase the risk of abdominal cavity contamination. Similarly, Siotos et al. [22] found that irrigation was not a protective factor but instead suggested that its use increased the odds of IAA development after LA. Irrigation also significantly increased LA operative time by approximately 7 minutes. In accordance with previous reports, we found that operative time was significantly longer in the irrigation group than it was in the suction only group, and SSI rate was higher. Although the mean difference in operative time was only 4.1 minutes, it was significantly significant. Regardless, an operative time $>90 \mathrm{~min}-$ utes was not a risk factor for SSI after LA in this study. Thus, peritoneal irrigation may prolong LA operative time. Further studies are needed to define the relationship between operative time and incidence of SSI after LA.

This study has several limitations. It was performed at a single center with a small sample size. Its retrospective design may also have introduced selection bias. Although we focused on cases of uncomplicated appendicitis, inflammation severity was still variable. For instance, patients in whom the surgeon decided to perform irrigation may have had more inflammation than those who did not receive irrigation. Differences in inflammation, therefore, may have explained the higher risk of postoperative complications in patients who underwent irrigation compared to those who did not. The amount of irrigation may be an important fac- 
tor affecting postoperative complication rate. However, we could not assess irrigation amount given the retrospective design of our study. In addition, operative time was influenced by factors such as skill of surgeon, methods of wound closure, and intra-abdominal adhesion, which we were unable to assess. Therefore, a welldesigned prospective study is needed to clarify the effect of peritoneal irrigation during LA in uncomplicated appendicitis.

In summary, there is no advantage to irrigation of the peritoneal cavity over suction alone during LA in uncomplicated appendicitis. Irrigation may prolong the operative time. Peritoneal cavity irrigation may also increase the incidence of SSI after LA. Therefore, we cannot recommend routine irrigation during LA for uncomplicated acute appendicitis.

\section{CONFLICTS OF INTEREST}

The authors have no conflicts of interest to declare.

\section{ACKNOWLEDGMENTS}

This study was supported by a faculty research grant from the $\mathrm{Na}-$ tional Health Insurance Service Ilsan Hospital (NHIMC2017CR071).

\section{REFERENCES}

1. Guller U, Hervey S, Purves H, Muhlbaier LH, Peterson ED, Eubanks S, et al. Laparoscopic versus open appendectomy: outcomes comparison based on a large administrative database. Ann Surg 2004;239:43-52.

2. Katkhouda N, Mason RJ, Towfigh S, Gevorgyan A, Essani R. Laparoscopic versus open appendectomy: a prospective randomized double-blind study. Ann Surg 2005;242:439-48.

3. Yau KK, Siu WT, Tang CN, Yang GP, Li MK. Laparoscopic versus open appendectomy for complicated appendicitis. J Am Coll Surg 2007;205:60-5.

4. Markides G, Subar D, Riyad K. Laparoscopic versus open appendectomy in adults with complicated appendicitis: systematic review and meta-analysis. World J Surg 2010;34:2026-40.

5. Cho J, Park I, Lee D, Sung K, Baek J, Lee J. Risk factors for postoperative intra-abdominal abscess after laparoscopic appendectomy: analysis for consecutive 1,817 experiences. Dig Surg 2015;32: 375-81.

6. Kim TH, Cho BS, Jung JH, Lee MS, Jang JH, Kim CN. Predictive factors to distinguish between patients with noncomplicated appendicitis and those with complicated appendicitis. Ann Coloproctol 2015;31:192-7.

7. Fike FB, Mortellaro VE, Juang D, Sharp SW, Ostlie DJ, St Peter SD. The impact of postoperative abscess formation in perforated appendicitis. J Surg Res 2011;170:24-6.

8. Schlottmann F, Sadava EE, Peña ME, Rotholtz NA. Laparoscopic appendectomy: risk factors for postoperative intraabdominal ab- scess. World J Surg 2017;41:1254-8.

9. Sun F, Wang H, Zhang F, Zhang X, Xing Z, Zhang S, et al. Copious irrigation versus suction alone during laparoscopic appendectomy for complicated appendicitis in adults. J Invest Surg 2018;31:342-6.

10. Hussain A, Mahmood H, Nicholls J, El-Hasani S. Prevention of intra-abdominal abscess following laparoscopic appendicectomy for perforated appendicitis: a prospective study. Int J Surg 2008;6: 374-7.

11. Moore CB, Smith RS, Herbertson R, Toevs C. Does use of intraoperative irrigation with open or laparoscopic appendectomy reduce post-operative intra-abdominal abscess? Am Surg 2011;77: 78-80.

12. St Peter SD, Adibe OO, Iqbal CW, Fike FB, Sharp SW, Juang D, et al. Irrigation versus suction alone during laparoscopic appendectomy for perforated appendicitis: a prospective randomized trial. Ann Surg 2012;256:581-5.

13. Clavien PA, Barkun J, de Oliveira ML, Vauthey JN, Dindo D, Schulick RD, et al. The Clavien-Dindo classification of surgical complications: five-year experience. Ann Surg 2009;250:187-96.

14. Berríos-Torres SI, Umscheid CA, Bratzler DW, Leas B, Stone EC, $\mathrm{Kelz} \mathrm{RR}$, et al. Centers for disease control and prevention guideline for the prevention of surgical site infection, 2017. JAMA Surg 2017;152:784-91.

15. Sookhai S, Redmond HP, Deasy JM. Impervious wound-edge protector to reduce postoperative wound infection: a randomised, controlled trial. Lancet 1999;353:1585.

16. Abrams P, Cardozo L, Fall M, Griffiths D, Rosier P, Ulmsten U, et al. The standardisation of terminology in lower urinary tract function: report from the standardisation sub-committee of the International Continence Society. Urology 2003;61:37-49.

17. St Peter SD, Holcomb GW 3rd. Should peritoneal lavage be used with suction during laparoscopic appendectomy for perforated appendicitis? Adv Surg 2013;47:111-8.

18. Abbasoglu O, Sayek I, Hascelik G. The effect of peritoneal lavage on peritoneal cellular defense mechanisms. Acta Chir Belg 1994; 94:321-4.

19. Yaacobi Y, Goldberg EP, Habal MB. Effect of Ringer's lactate irrigation on the formation of postoperative abdominal adhesions. J Invest Surg 1991;4:31-6.

20. Snow HA, Choi JM, Cheng MW, Chan ST. Irrigation versus suction alone during laparoscopic appendectomy; a randomized controlled equivalence trial. Int J Surg 2016;28:91-6.

21. Fraser JD, Aguayo P, Sharp SW, Snyder CL, Holcomb GW 3rd, Ostlie DJ, et al. Physiologic predictors of postoperative abscess in children with perforated appendicitis: subset analysis from a prospective randomized trial. Surgery 2010;147:729-32.

22. Siotos C, Stergios K, Prasath V, Seal SM, Duncan MD, Sakran JV, et al. Irrigation versus suction in laparoscopic appendectomy for complicated appendicitis: a meta-analysis. J Surg Res 2019;235: 237-43. 